\title{
1,2-Dichloropropane (1,2-DCP)-Induced Angiogenesis in Dermatitis
}

\author{
Meiying Jin ${ }^{1, \dagger}$, Youngeun Hong ${ }^{2,3, \dagger}$, Hyunji Lee ${ }^{2,3, \dagger}$, Quangdon Tran ${ }^{2,3}$, Hyeonjeong Cho ${ }^{2,3}$, \\ Minhee Kim ${ }^{2,3}$, So Hee Kwon ${ }^{4}$, Nak Heon Kang ${ }^{1}$, Jisoo Park ${ }^{2,3}$ and Jongsun Park ${ }^{2,3}$ \\ ${ }^{1}$ Department of Plastic and Reconstructive Surgery, College of Medicine, Chungnam National University, Daejeon, \\ Korea \\ ${ }^{2}$ Department of Pharmacology, Metabolic Syndrome and Cell Signaling Laboratory, Institute for Cancer Research, \\ College of Medicine, Chungnam National University, Daejeon, Korea \\ ${ }^{3}$ Department of Medical Science, College of Medicine, Chungnam National University, Daejeon, Korea \\ ${ }^{4}$ College of Pharmacy, Yonsei Institute of Pharmaceutical Sciences, Yonsei University, Incheon, Korea
}

\begin{abstract}
1,2-Dichloropropane (1,2-DCP) has been used as an industrial solvent and a chemical intermediate, as well as in soil fumigants. Human exposure may occur during its production and industrial use. The target organs of 1,2-DCP are the eyes, respiratory system, liver, kidneys, central nervous system, and skin. Repeated or prolonged contact may cause skin sensitization. In this study, 1,2-DCP was dissolved in corn oil at $0,2.73,5.75$, and $8.75 \mathrm{~mL} / \mathrm{kg}$. The skin of mice treated with 1,2-DCP was investigated using western blotting, hematoxylin and eosin staining, and immunohistochemistry. 1,2-DCP was applied to the dorsal skin and both ears of C57BL/6J mice. The thickness of ears and the epidermis increased significantly following treatment, and the appearance of blood vessels was observed in the dorsal skin. Additionally, the expression of vascular endothelial growth factor, which is tightly associated with neovascularization, increased significantly. The levels of protein kinase-B (PKB), phosphorylated PKB, mammalian target of rapamycin (mTOR), and phosphorylated mTOR, all of which are key components of the phosphoinositide 3-kinase/PKB/mTOR signaling pathway, were also enhanced. Taken together, 1,2-DCP induced angiogenesis in dermatitis through the PI3K/PKB/mTOR pathway in the skin.
\end{abstract}

Key words: 1,2-Dichloropropane, VEGF, Angiogenesis, Skin, NHFD cell

\section{INTRODUCTION}

1,2-Dichloropropane (1,2-DCP) is an organic compound classified as a chlorocarbon (1). It is also referred to as chloromethyl chloride, propylene chloride, propylene bichloride, propylene dichloride, and dichloro-1,2 propane
(2). 1,2-DCP is a volatile organic chemical consisting of one hydrocarbon with two chlorines (1). It is obtained as a byproduct of the synthesis of propylene oxide by the chlorohydrin reaction (3). 1,2-DCP was originally used as a fumigant to control root parasitic nematodes in agriculture (4-6). Due to its carcinogenicity and environmental
Correspondence to: Jisoo Park, Department of Pharmacology, Metabolic Syndrome and Cell Signaling Laboratory, Institute for Cancer Research, and Department of Medical Science, College of Medicine, Chungnam National University, 266 Munhwa-Ro, JungGu, Daejeon 35015, Korea

E-mail: basel97@cnu.ac.kr

Jongsun Park, Department of Pharmacology, Metabolic Syndrome and Cell Signaling Laboratory, Institute for Cancer Research, and Department of Medical Science, College of Medicine, Chungnam National University, 266 Munhwa-Ro, Jung-Gu, Daejeon 35015, Korea

E-mail: insulin@cnu.ac.kr

\section{${ }^{\dagger}$ The first three authors contributed equally to this work.}

List of abbreviations: 1,2-DCP, 1,2-Dichloropropane; IL-6, Interleukin-6; NHFD cell, Normal human fibroblast cell; TNF- $\alpha$, Tumor necrosis factor alpha; VEGF, Vascular endothelial growth factor.

This is an Open-Access article distributed under the terms of the Creative Commons Attribution Non-Commercial License (http:// creativecommons.org/licenses/by-nc/3.0) which permits unrestricted non-commercial use, distribution, and reproduction in any medium, provided the original work is properly cited. 
persistence, 1,2-DCP and other types of halogenated propanes have been replaced and are no longer applied to crops (7).

1,2-DCP has also been widely used as an industrial solvent or chemical intermediate during the production of chlorinated organic chemicals $(8,9)$. 1,2-DCP is still used as a textile stain remover, solvent, lead scavenger in antiknock fluids, oil and paraffin extractant, paint and furniture finish remover, and metal-degreasing agent. Sublethal contact can lead to inhibition of the central nervous system $(10,11)$. In rats, short-term exposure of 1,2-DCP by inhalation has been shown to cause liver injury (12).

Most known cases of human 1,2-DCP poisoning involve accidental intake of substances contained in cleansers and solvents $(13,14)$. Symptoms following the ingestion of 1,2-DCP include liver and kidney disorders (high levels of asparagine and alanine transaminase, bilirubin, and creatinine and reduced levels of prothrombin), hemolytic anemia, metabolic acidosis, heart muscle weakness, and shock. However, there is no direct data regarding the effects of skin absorption. Systemic effects, such as death, have been shown to occur following the application of 1,2-DCP to rabbit skin. It is known that $1,2-\mathrm{DCP}$ is absorbed through the skin (15).

The carcinogenicity of 1,2-DCP was evaluated in animal studies of rats and mice. Inhalation studies showed that exposure to 1,2-DCP increased the incidence of nasal tumors in male and female rats, lung tumors in female rats, and Harderian gland tumors in male mice $(16,17)$. However, it was recently shown that inhalation of 1,2DCP through the respiratory tract may lead to cholangiocarcinoma. In 2012, several workers in Japan working in an offset printing company suffered from cholangiocarcinoma. During the process of ink removal, they were exposed to a high concentration of 1,2-DCP for a long period of time (18). In 2014, the International Agency for Research on Cancer (IARC) reclassified 1,2-DCP from Group 3 to Group 1 (carcinogenic to humans) (19).

Angiogenesis is the physiological process by which new blood vessels are formed from previously existing vessels. Although angiogenesis is required during growth and development, abnormal angiogenesis has been linked to a number of human diseases, including cancer, cardiovascular disease, diabetes, age-related macular degeneration, and diabetic retinopathy (19-22). Vascular endothelial growth factor (VEGF), originally known as vascular permeability factor, has the potential to induce the accumulation of ascites fluid due to the activity of tumor cells (23). The VEGF pathway accelerates angiogenesis (24). When VEGF interacts with its receptors in normal endothelial cells, the phosphoinositide 3-kinase (PI3K) and RAS pathways are activated. The mammalian target of rapamycin (mTOR) is downstream of the VEGF receptor (VEGFR)/PI3K/protein kinase $\mathrm{B}$ (PKB) pathway (25).
Cholangiocarcinoma was found among the workers who inhaled 1,2-DCP at work in a printing company, Japan. 1,2-DCP can also be absorbed through the skin into the blood circulation, causing internal damage. However, few studies have determined the effects of 1,2-DCP applied to the skin. Therefore, we conducted this study to investigate the effect of 1,2-DCP on the skin, by applying the agent to the dorsal skin and both ears of $\mathrm{C} 57 \mathrm{BL} / 6 \mathrm{~J}$ mice. Dermatitis and vascular proliferation were both observed. To clarify the mechanisms of 1,2-DCP-induced dermatitis and angiogenesis, we performed immunohistochemistry (IHC) and western blotting, to assess protein expression of the pro-inflammatory cytokines interleukin (IL)-6 and tumor necrosis factor (TNF)- $\alpha$ and the angiogenesis factor VEGF.

\section{MATERIALS AND METHODS}

Reagents and antibodies. 1,2-DCP (99\%) and corn oil were obtained from Sigma-Aldrich Co (St. Louis, MO, USA). The following antibodies were used: anti-VEGF (Santa Cruz Biotechnology Inc., Dallas, TX, USA), antiphosphorylated PKB (p-PKB; Cell Signaling, Danvers, MA, USA), anti-PKB (Cell Signaling), anti-phosphorylated mTOR (p-mTOR; Cell Signaling), anti-mTOR (Cell Signaling), anti-TNF- $\alpha$ (Abcam, Cambridge, UK), antiIL-6 (Invitrogen, Carlsbad, CA, USA), anti-actin (SigmaAldrich Co.), and anti-mouse or anti-rabbit secondary antibodies (Koma Biotech, Seoul, Korea).

Animals. C57BL/6J mice (6-week-old) were purchased from Jungang Animal Company (Seoul, Korea). Mice were observed for 1 day during acclimation and divided into four groups ( $\mathrm{n}=5$ per group): (1) negative control $0 \mathrm{~mL} / \mathrm{kg}$ 1,2-DCP, (2) $2.73 \mathrm{~mL} / \mathrm{kg} \mathrm{1,2-DCP,} \mathrm{(3)} 5.75 \mathrm{~mL} /$ $\mathrm{kg}$ 1,2-DCP, and (4) $8.75 \mathrm{~mL} / \mathrm{kg}$ 1,2-DCP. All groups were maintained under standard temperature $\left(22.5 \pm 0.5^{\circ} \mathrm{C}\right)$ and humidity $(42.6 \pm 1.7 \%)$ conditions. The experimental protocol used in this study has been approved by the Animal Care and Ethics Committee of Chungnam National University. All animal-handling procedures were performed according to the Guide of the Care and Use of Laboratory Animals of the Korea National Institutes of Health, and followed the guidelines of the Animal Welfare Act.

Cell lines. Normal human dermal fibroblast (NHDF) cells were maintained in Dulbecco's modified Eagle's medium (1:1) containing 10\% fetal bovine serum and 1\% antibiotic. NHDF cells were grown at $37^{\circ} \mathrm{C}$ in humidified $5 \% \mathrm{CO}_{2}$.

Drug treatment. When 1,2-DCP is applied to the skin, the $\mathrm{LD}_{50}$ is $8.75 \mathrm{~mL} / \mathrm{kg}$, but the effects at $2.73 \mathrm{~mL} / \mathrm{kg}$ are unknown. In this experiment, we tested the following 
concentrations: $0,2.73,5.75$, and $8.75 \mathrm{~mL} / \mathrm{kg}$ (26). 1,2DCP was dissolved in corn oil. After 1 day of acclimation, the dorsal hair of mice was completely removed, followed by treatment with the various concentrations of 1,2DCP $(0,2.73,5.75$, and $8.75 \mathrm{~mL} / \mathrm{kg})$ on the dorsal skin and both ears of mice, once a day for 7 days, while the control group was treated with coin oil without 1,2-DCP. After 7 days, the mice were sacrificed and dorsal skin was collected for subsequent experiments.

Euthanasia in mice. Avertin used in anesthetics dissolve 2.5 grams in $5 \mathrm{~mL}$ amylene hydrate. And adding distilled water, up to a final volume of $200 \mathrm{~mL}$. Next, this material was filtered through a $0.22 \mu \mathrm{m}$ size filter. The material is given by Intraperitoneal injection at a dose of $250 \mathrm{mg} / \mathrm{kg}$.

Ear thickness measurements. Ear thickness were measured as an indirect method of determining skin inflammation caused by DCP. For each mouse, ear thickness was measured and recorded with a micrometer (Mitutoyo, Kawasaki, Japan). To minimize variation, a single investigator performed all measurements.

Histopathological analysis. At the end of the study period, the dorsal skin lesions of each mouse were removed, fixed with $10 \%$ neutral-buffered formalin, and embedded in paraffin. Sections of $4-\mu \mathrm{m}$ thickness were stained with hematoxylin and eosin (H\&E) to measure epidermal thickness. Histopathological evaluation of all skin sections was performed in a blind fashion. All samples were observed using an inverted microscope and data are representative of five observations (Nikon Eclipse Ti; Nikon, Tokyo, Japan).

IHC staining procedure. All specimens were fixed in $10 \%$ formalin and $4-6 \mu \mathrm{m}$ sections were cut on glass slides for routine H\&E staining. Sections were deparaffinized and rehydrated with graded alcohol to water. The avidin-biotin-peroxidase method and 3,3-diaminobenzidine chromogen were applied for IHC analysis. Endogenous peroxidase activity was blocked with $0.6 \%$ hydrogen peroxide. After blocking, sections were incubated at $4^{\circ} \mathrm{C}$ for $12 \mathrm{hr}$ with antibodies against VEGF (Santa Cruz Biotechnology Inc.), IL-6 (Flarebio Biotech Co., Ltd., Wuhan, Hubei, China), and TNF- $\alpha$ (Abcam). The immunohistochemical markers were examined with an Olympus Korea Co (Seoul, Korea).

Western blot analysis. Western blot analysis was performed as the described previously (27). Protein lysates were prepared from the skin of mice and NHDF cells. Following treatment of NHDF cells with 1,2-DCP, cells were placed on ice, washed twice in ice-cold phosphate-buffered saline, and lysed at $4^{\circ} \mathrm{C}$ for $30 \mathrm{~min}$ in lysis buffer containing $50 \mathrm{mmol} / \mathrm{L}$ Tris- $\mathrm{HCl}, \mathrm{pH} 7.5,1 \%$ (v/v) Nonidet P-40 (NP-40), $250 \mathrm{mmol} / \mathrm{L} \mathrm{NaCl}, 0.1 \mathrm{mmol} / \mathrm{L}$ phenyl methyl sulfonyl fluoride (PMSF), $0.1 \mathrm{mmol} / \mathrm{L}$ sodium vanadate, $20 \mathrm{mmol} / \mathrm{L} \beta$-glycerol phosphate, $2 \mathrm{mmol} / \mathrm{L}$ dithiothreitol (DTT), $1 \mathrm{mmol} / \mathrm{L}$ leupeptin, and $10 \mathrm{mmol} / \mathrm{L}$ para-nitrophenylphosphate. The dorsal skin tissue from mice $(\sim 200 \mathrm{mg})$ was homogenized in lysis buffer with freshly added protease inhibitors using a mortar and pestle or sonication, and lysates were centrifuged at 13,000 $\times \mathrm{g}$ for $1 \mathrm{hr}$. Protein concentrations were determined according to the BCA protein assay and the standard plot was generated using bovine serum albumin. Protein samples $(60 \mu \mathrm{g})$ from the different concentrations of 1,2-DCP were denatured by boiling at $100^{\circ} \mathrm{C}$ for $3 \mathrm{~min}$ in sample buffer containing $\beta$-mercaptoethanol. Protein was separated by $10 \%$ sodium dodecyl sulfate polyacrylamide gel electrophoresis and transferred to nitrocellulose membranes. After blocking with 5\% skim milk in Tris-buffered saline (TBS) containing $0.02 \%$ Tween-20 at room temperature for $1 \mathrm{hr}$, the blots were incubated with primary antibody $(1: 1,000)$ overnight at $4^{\circ} \mathrm{C}$ and $\beta$-actin $(1: 5,000)$ was used as a loading control. Following incubation with primary antibodies, blots were washed four times for $15 \mathrm{~min}$ in TBS/Tween-20 before incubation for $1 \mathrm{hr}$ at room temperature with goat anti-mouse or anti-rabbit horse radish peroxidase-conjugated antibody $(1: 2,000)$ in TBS/Tween20 containing 5\% skim milk. Proteins were detected with an enhanced chemiluminescence kit (Amersham Biosciences, Buckinghamshire, UK).

Statistical analysis. Quantification of western blot analysis was carried out using ImageJ software (NIH, Bethesda, MD, USA). An overall difference between more than two groups was determined using a one-way ANOVA. If oneway ANOVAs were significant, differenced between individual groups were estimated using a Dunnett's Multiple comparison test. All calculations and data plotting were performed using GraphPad Software (San Diego, CA, USA). Data are presented as means \pm standard deviation. A $p$ value $<0.05$ was considered significant, compared with corresponding control values.

\section{RESULTS}

Effects of 1,2-DCP on skin thickness in mice. To investigate the effects of 1,2-DCP on normal mouse skin, we applied 1,2-DCP to the dorsal skin and both ears for 7 days. The concentrations tested were $0,2.73,5.75$, and $8.75 \mathrm{~mL} / \mathrm{kg}$ (26), and the experimental scheme is summarized in Fig. 1A. The top photograph in Fig. 1B reflects the first day of the experiment, immediately after shaving, and the photograph below shows the dorsal image of mice after 7 days of daily treatment with 1,2-DCP. After 7 days of treatment, ear thickness increased significantly in a 
(A)

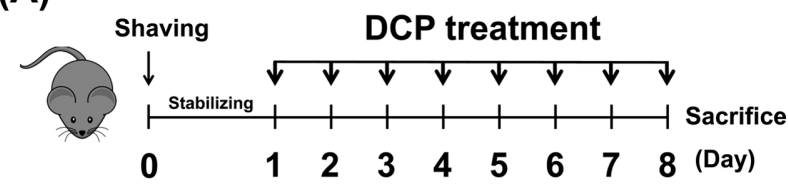

(B)

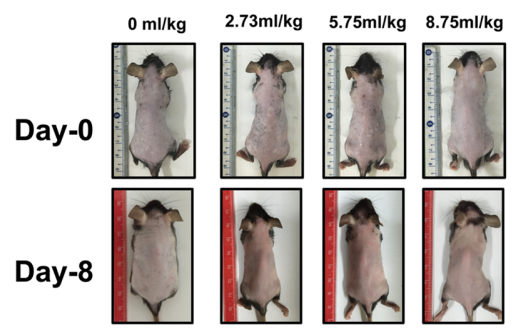

(C)
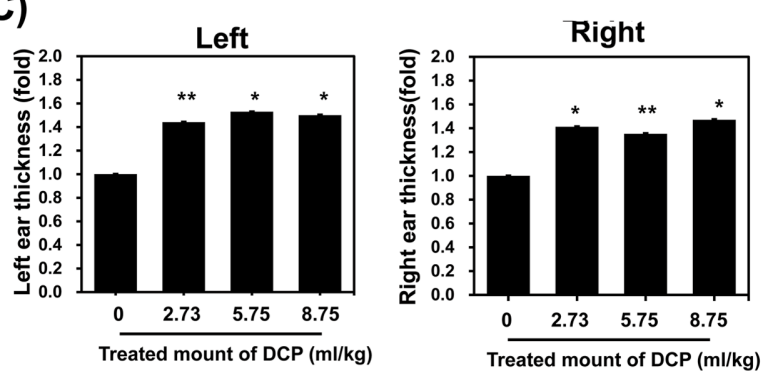

(D)

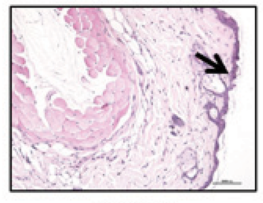

$0 \mathrm{ml} / \mathrm{kg}$
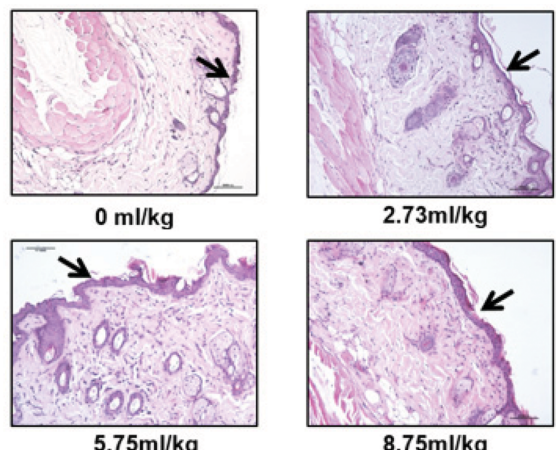

$2.73 \mathrm{ml} / \mathrm{kg}$

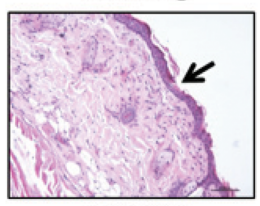

$8.75 \mathrm{ml} / \mathrm{kg}$
(A)

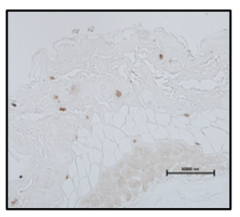

$0 \mathrm{ml} / \mathrm{kg}$

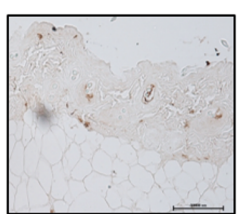

$5.75 \mathrm{ml} / \mathrm{kg}$

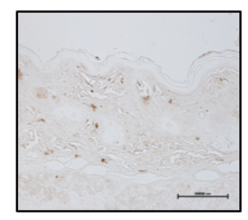

$2.73 \mathrm{ml} / \mathrm{kg}$

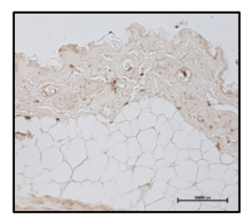

$8.75 \mathrm{ml} / \mathrm{kg}$

(B)

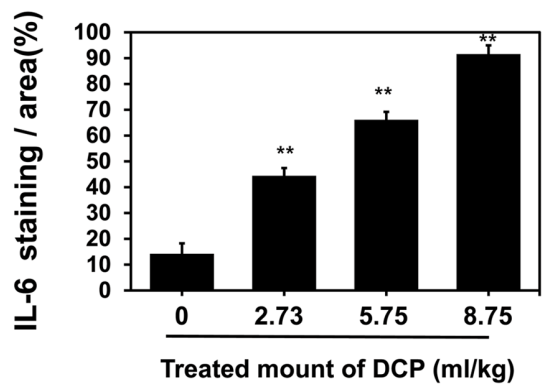

(C)
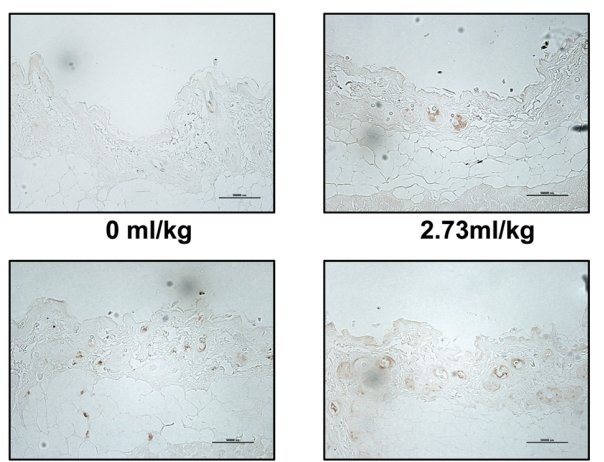

$5.75 \mathrm{~m} / \mathrm{kg}$

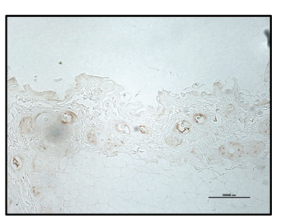

$8.75 \mathrm{~m} / \mathrm{kg}$

(D)

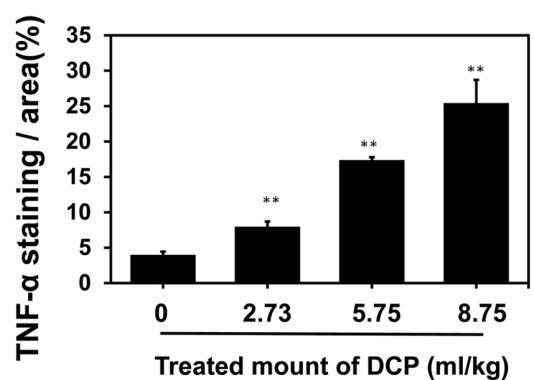

Fig. 2. Effects of 1,2-DCP on the expression of pro-inflammatory cytokines in 1,2-DCP-treated mice. (A) Immunohistochemistry (IHC) of interleukin (IL)-6 in dorsal skin treated with 1,2DCP (brown staining considered positive; 400x, scale bar $=$ $10 \mu \mathrm{m}$ ). (C) IHC of skin tumor necrosis factor (TNF)- $\alpha$ in dorsal skin treated with 1,2-DCP (brown staining considered positive; $400 \times$, scale bar $=10 \mu \mathrm{m})$. (B, D) Quantification of IHC-positive areas in the skin is shown on the right. The data were analyzed by Image-Pro Plus software (Media Cybernetics, Silver Spring, MD, USA). The results are means \pm SD of two independent experiments. ${ }^{* *} p<0.01$. 
dose-dependent manner (Fig. 1C). We also performed H\&E staining of the dorsal skin and observed the tissue under an optical microscope. Dorsal histopathological results showed thickening of the epidermis in a dose-dependent manner in 1,2-DCP-treated mice (Fig. 1D). These results suggest that inflammatory reactions may have occurred.

\section{1,2-DCP increases pro-inflammatory cytokine expres-} sion. A previous study reported that 1,2-DCP induced contact dermatitis (28). Moreover, pro-inflammatory cyto-

(A)
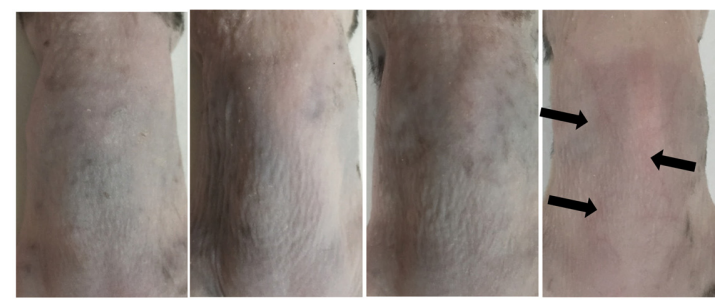

$0 \mathrm{ml} / \mathrm{kg} \quad 2.73 \mathrm{ml} / \mathrm{kg}$

$5.75 \mathrm{ml} / \mathrm{kg}$

$8.75 \mathrm{ml} / \mathrm{kg}$

(B)
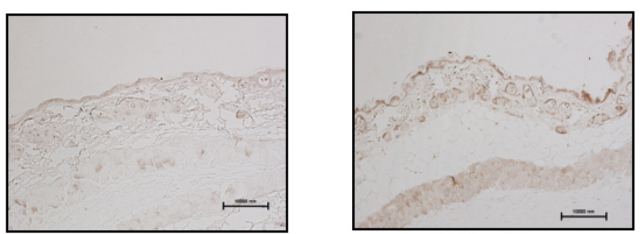

$0 \mathrm{ml} / \mathrm{kg}$

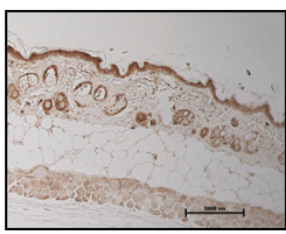

$5.75 \mathrm{ml} / \mathrm{kg}$

$2.73 \mathrm{ml} / \mathrm{kg}$

(C)

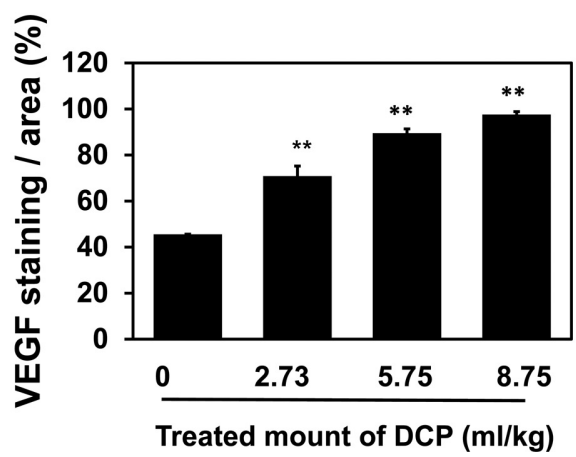

Fig. 3. $1,2-D C P$ enhanced angiogenic signaling. (A) In 1,2-DCPtreated mice, the challenged dorsal skin remained vascularized. (B) Immunofluorescence of vascular endothelial growth factor (VEGF) following 1,2-DCP treatment in mice. (C) Quantification of IHC-positive areas in the skin is shown on the right. The data were analyzed by Image-Pro Plus software. Mice treated with 1,2-DCP at each indicated concentration $(0,2.73$, 5.75 , and $8.75 \mathrm{~mL} / \mathrm{kg}$ ) for 7 days $(400 \times$, scale bar $=10 \mu \mathrm{m})$. The results are means \pm SD of two independent experiments. ${ }^{* *} p<$ 0.01 . kines, such as IL- 6 and TNF- $\alpha$, were unregulated during the contact reaction (29). In the present study, mice were treated with 1,2-DCP for 7 days. After completion of treatment, the dorsal skin was collected. To determine whether 1,2-DCP treatment induced dermatitis, the pro-inflammatory cytokines IL- 6 and TNF- $\alpha$ were detected by IHC staining, which showed that their expression levels were higher than in the control groups, and increased in a dosedependent manner (Fig. 2A, 2C). Quantification of IHC staining-positive areas in the skin is shown in Fig. 2B, 2D. Together, this finding suggests that 1,2-DCP induces dermatitis, and an increased co ncentration of 1,2-DCP results in increased expression of pro-inflammatory factors.

\section{1,2-DCP induced angiogenesis through activation of} the PI3K signaling pathway. VEGF is a potent angiogenic factor having effects on endothelial cells that are mediated by the PI3K pathway (30). mTOR is a downstream target of the VEGFR/PI3K/PKB pathway (31). We observed that blood vessels were enlarged in the dorsal skin of mice treated with 1,2-DCP for 7 days (Fig. 3A). VEGF also showed higher expression in 1,2-DCP-treated sections compared with the control in a dose-dependent manner (Fig. 3B, 3C). To further study the mechanisms underlying VEGF-driven angiogenesis in 1,2-DCP-administered mice, we performed western blotting to assess pAKT and p-mTOR activity, which are both important in the PI3K/AKT/mTOR signaling pathway. As shown in Fig. 4, the protein levels of p-AKT and p-mTOR increased significantly in a dose-dependent manner. 1,2-DCP increased cell proliferation and angiogenesis by activating the PI3K signaling pathway. These results suggested that the PI3K signaling pathway was activated in 1,2-DCP-treated mice.

\section{1,2-DCP induced angiogenesis through activation of} the PI3K signaling pathway in NHFD cells. NHDF cells were treated with 1,2-DCP at doses of 2.73, 5.75, and $8.75 \mu \mathrm{L} / \mathrm{mL}$ for $24 \mathrm{hr}$ and imaged. Cells treated with 5.75 and $8.75 \mu \mathrm{L} / \mathrm{mL}$ 1,2-DCP exhibited an increased rate of cell death compared with untreated control cells (Fig. 5A). As shown in Fig. 5A, treatment of cell with $8.75 \mu \mathrm{L} / \mathrm{mL}$ 1,2-DCP caused the cell-death. Therefore, it was not possible to recover the cell extracts from the treatment of cell with $8.75 \mu \mathrm{L} / \mathrm{mL}$ 1,2-DCP. Protein extracts of untreated and 1,2-DCP-treated cells were analyzed by western blotting. Some studies have shown that pro-inflammatory cytokines, such as IL- 6 and TNF- $\alpha$, are unregulated during inflammation (29). VEGF induces angiogenesis through the PI3K/PKB pathway (32) and mTOR is a downstream target of the VEGFR/PI3K/PKB pathway (31). Our results showed that protein levels of IL-6, TNF- $\alpha$, VEGF, p-AKT, and $\mathrm{p}-\mathrm{mTOR}$ were increased in a dose-dependent manner (Fig. 5B-5H). These data indicate that 1,2-DCP not only induces inflammation, but also induces angiogenesis in 


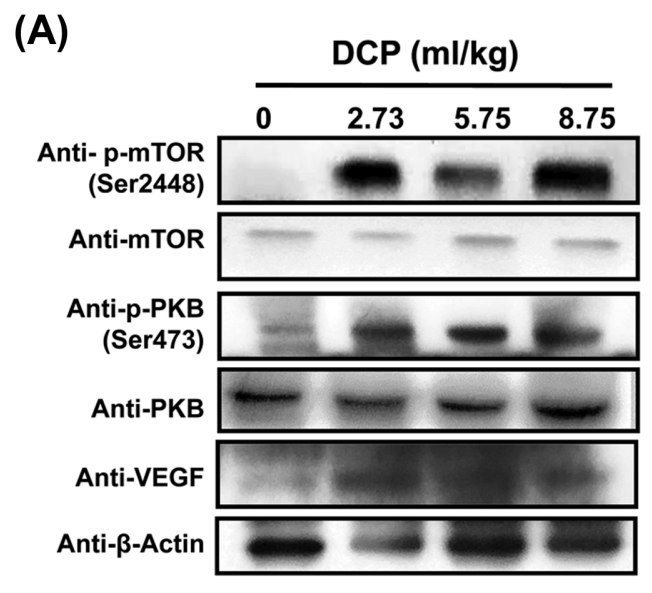

(B)

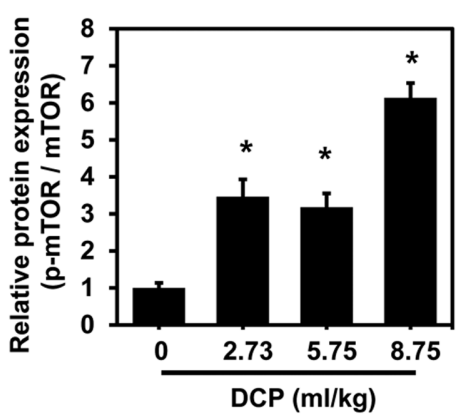

(C)

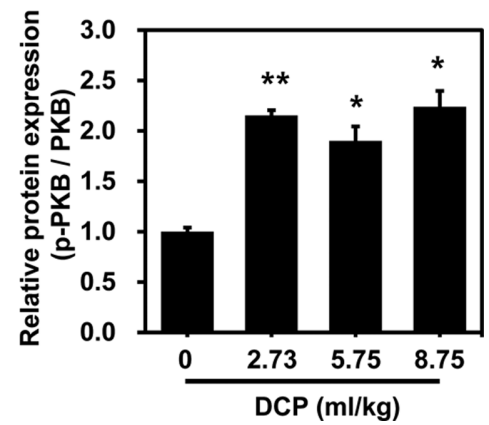

Fig. 4. Protein expression of VEGF, phosphorylated protein kinase $B$ ( $p-P K B)$, and phosphorylated mammalian target of rapamycin (p-mTOR) in the angiogenic sites. (A) Western blot analysis of VEGF, p-PKB, and p-mTOR following 1,2-DCP treatment in mice. Actin was used as a loading control. $(B, C)$ Graph shows densitometric quantification of bands. The results are means $\pm S D$ of two independent experiments. ${ }^{*} p<0.05 ;{ }^{* *} p<0.01$.

NHFD cells through the PI3K signaling pathway.

\section{DISCUSSION}

1,2-DCP is a chemical intermediate that is used as a solvent in industry, and as an insecticide fumigant in agriculture (33). Acute exposure to 1,2-DCP can cause damage to the liver and kidneys in humans and animals (34). It is also used as a cleaner in offset-printing processes in Japan. In 2012, workers of an offset proof-printing company in Japan suffered from cholangiocarcinoma following longterm exposure to high levels of 1,2-DCP during ink removal operations (35). In 2014, the IARC reclassified 1,2-DCP from Group 3 to Group 1 (carcinogenic to humans) (18). Several younger employees who were exposed to halohydrocarbon solvents mainly composed of 1,2-DCP for a long period of time developed occupational cholangiocarcinoma (36). For workers involved in the production or use of 1,2-DCP, there is a risk of chemical exposure by inhalation or dermal contact. However, little attention has been paid to the impact of 1,2-DCP on the skin.

In the present study, we applied 1,2-DCP to the dorsal skin and both ears of mice for 7 days. We observed that ear and dorsal skin thickness increased in a dose-dependent manner (Fig. 1). Moreover, the expression levels of the pro-inflammatory cytokines TNF- $\alpha$ and IL- 6 were upregulated in a dose-dependent manner (Fig. 2).

Dermatitis is known to result in dysfunction of the epi- dermal barrier. The preformed IL- $1 \beta$ is released by disruption of the skin barrier, and is the first step in the inflammatory cascade of contact dermatitis (32). Activated IL-1 $\beta$ stimulates further production of proinflammatory cytokines and chemokines, such as IL- $1 \beta$, TNF- $\alpha$, and IL6 , by surrounding epidermal and dermal cells $(32,33)$. Our results revealed that 1,2-DCP application on the skin of mice induced dermatitis.

Following treatment with 1,2-DCP, vascular proliferation was observed in the dorsal skin in the group of mice treated with the highest concentration of 1,2-DCP (Fig. $3 \mathrm{~A})$. Angiogenesis begins with vasodilation. The increased vascular permeability in response to VEGF allows the extravasation of plasma proteins, and the plasma protein deposition is used as a provisional scaffold for migrating endothelial cells (37). VEGF is an important signaling protein involved in both vasculogenesis and angiogenesis (38). It is secreted primarily by keratinocytes and is an effective mediator of angiogenesis (39). TNF- $\alpha$ (40) and IL-6 (41) can potentiate VEGF production. TNF- $\alpha$ has also been shown to induce angiogenesis in a variety of experimental models (19). In this study, vascular dilation was observed in dorsal mice treated with 1,2-DCP and the expression level of VEGF increased in a dose-dependent manner, as assessed by western blotting and IHC. Thus, we confirmed that 1,2-DCP induces angiogenesis.

VEGF is an effective angiogenic factor, and its effect on endothelial cells is mediated by the PI3K pathway (30). 
(A)

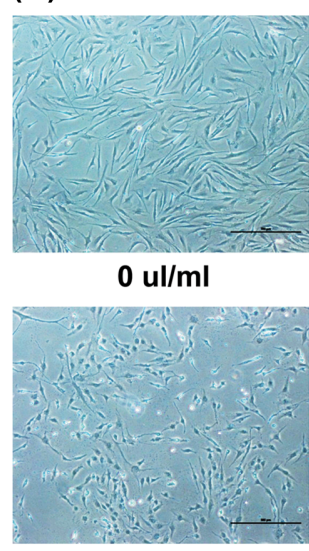

$5.75 \mathrm{ul} / \mathrm{ml}$

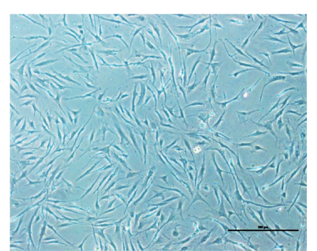

$2.73 \mathrm{ul} / \mathrm{ml}$

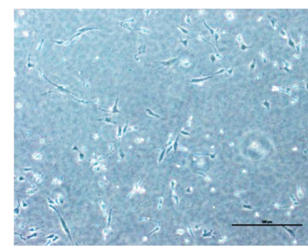

$8.75 \mathrm{ul} / \mathrm{ml}$

(C)

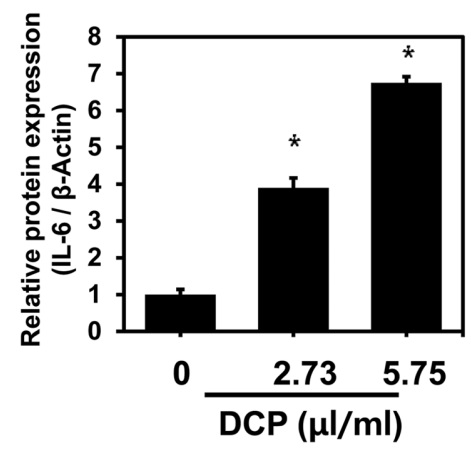

(E)

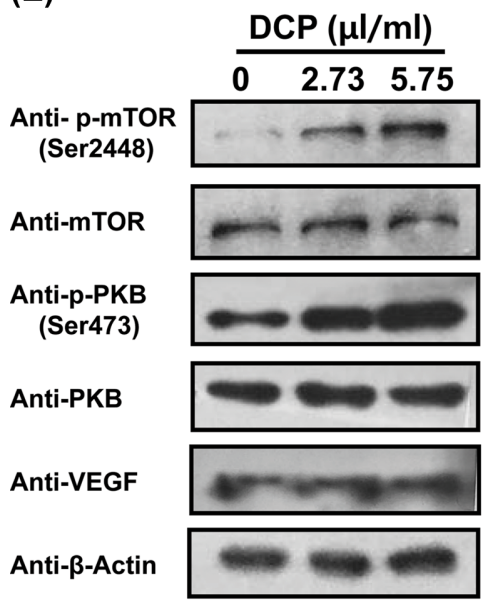

(B)

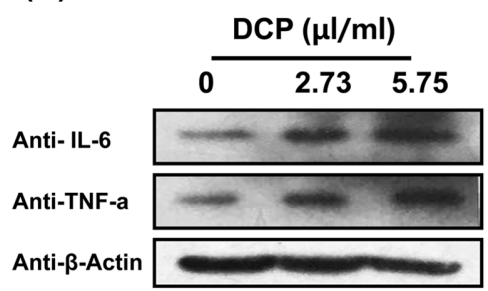

(D)

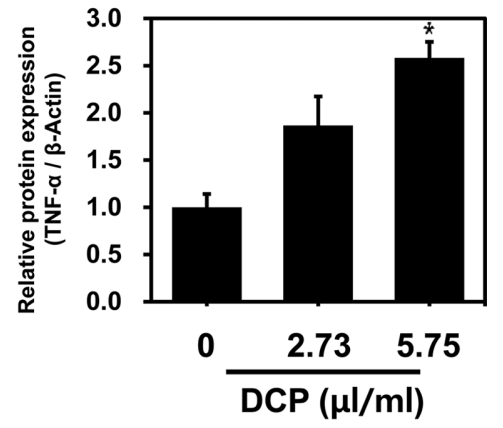

(F)

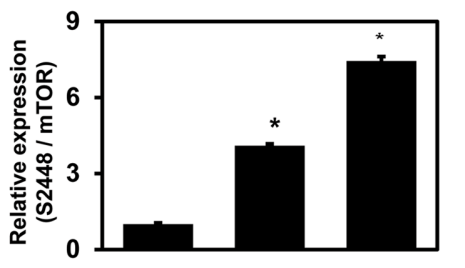

(G)

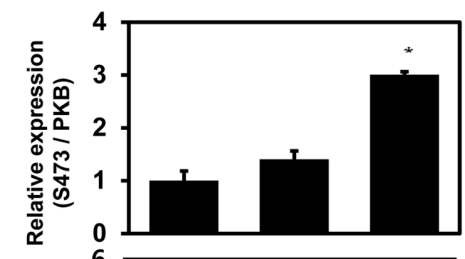

(H)

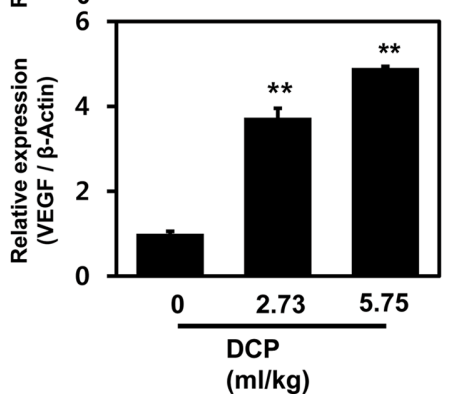

Fig. 5. 1,2-DCP induces inflammation and activates angiogenic signals in NHFD cells. (A) NHFD cells $\left(1 \times 10^{6}\right)$ were grown in $3.5 \mathrm{~mm}$ diameter cell culture dishes and treated with 1,2-DCP at doses of $0,2.73,5.75$, and $8.75 \mu \mathrm{L} / \mathrm{mL}$ for $24 \mathrm{hr}$ and imaged. (B, E) Western blot analysis of IL-6, TNF- $\alpha$, VEGF, p-PKB, and p-mTOR following 1,2-DCP treatment in NHFD cells. Actin was used as a loading control. The graph shows densitometric quantification of bands. $(C, D, F-H)$ The results are means $\pm S D$ of two independent experiments. ${ }^{*} p<0.05 ;{ }^{* *} p<0.01$. 
The phosphatase and tensin homolog (PTEN) gene encodes a phosphatase that counteracts the effect of PI3K, thereby reducing the level of activated $\mathrm{PKB}$, which controls protein synthesis and cell growth by triggering the phosphorylation of mTOR.

In this study, protein levels of AKT, p-AKT, mTOR, and p-mTOR, all of which are key factors of the PI3K/AKT/ mTOR signaling pathway, were shown to be increased by western blotting (Fig. 4). Thus, the PI3K/AKT/mTOR pathway was activated in 1,2-DCP-treated mice. The same experimental results were also obtained for 1,2-DCPtreated NHFD cells (Fig. 5). Activation of the PI3K/PKB/ mTOR pathway can increase the secretion of VEGF. The $\mathrm{PI} 3 \mathrm{~K} / \mathrm{PKB}$ pathway also regulates other angiogenic factors, such as nitric oxide and angiopoietins (42). Together, these findings reveal that $1,2-\mathrm{DCP}$ induced angiogenesis in dermatitis through the $\mathrm{P} 13 \mathrm{~K} / \mathrm{PKB} / \mathrm{mTOR}$ pathway in the skin.

When 1,2-DCP is in contact with skin, it increases the expression of inflammatory factors and angiogenesis factors, such as IL-6, TNF- $\alpha$ and VEGF, which induces dermatitis and angiogenesis. Therefore, these results clearly indicated and explained how 1,2-DCP can induced the cholangiocarcinoma in workers who were exposed to halohydrocarbon solvents mainly composed of 1,2-DCP for a long period of time previously (43). The observation of current report could be included as a mechanism of carcinogenesis for 1,2-DCP in the recent review about occupational cholangiocarcinoma (44).

\section{ACKNOWLEDGMENTS}

This study was supported by research fund of Chungnam National University (Jongsun Park) and Basic Science Research Program through the National Research Foundation of Korea, funded by the Ministry of Education (NRF2016K1A3A1A08953546, NRF-2014R1A1A3050752 and NRF-2015R1A2A2A01003597).

\section{CONFLICT OF INTEREST}

The authors have no conflict of interest to disclose.

Received May 21, 2019; Revised June 14, 2019; Accepted June 17, 2019

\section{REFERENCES}

1. Rossberg, M., Lendle, W., Pfleiderer, G., Tögel, A., Dreher, E.-L., Langer, E., Rassaerts, H., Kleinschmidt, P., Strack, H., Cook, R., Beck, U., Lipper, K.-A., Torkelson, T.R., Löser, E., Beutel, K.K. and Mann, T. (2006) Chlorinated Hydrocarbons in Ullmann's Encyclopedia of Industrial Chemistry, Wiley Online Library, Germany, pp. 11-25.

2. Agency for Toxic Substances and Disease Registry (2019)
Toxicological Profile for 1,2-Dichloropropane, Atlanta, GA, USA. Available from: http://www.atsdr.cdc.gov/ToxProfiles/ tp.asp?id $=831 \&$ tid $=162 /$.

3. Timchalk, C., Dryzga, M.D., Smith, F.A. and Bartels, M.J. (1991) Disposition and metabolism of [14C]1,2-dichloropropane following oral and inhalation exposure in Fischer 344 rats. Toxicology, 68, 291-306.

4. Fletcher, K.E., Löffler, F.E., Richnow, H.H. and Nijenhuis, I. (2009) Stable carbon isotope fractionation of 1,2-dichloropropane during dichloroelimination by Dehalococcoides populations. Environ. Sci. Technol., 43, 6915-6919.

5. Tesoriero, A.J., Löffler, F.E. and Liebscher, H. (2001) Fate and origin of 1,2-dichloropropane in an unconfined shallow aquifer. Environ. Sci. Technol., 35, 455-461.

6. Albrecht, W.N. and Chenchin, K. (1985) Dissipation of 1,2dibromo-3-chloropropane (DBCP), cis-1,3-dichloropropene (1,3-DCP), and dichloropropenes from soil to atmosphere. Bull. Environ. Contam. Toxicol., 34, 824-831.

7. Loffler, F.E., Champine, J.E., Ritalahti, K.M., Sprague, S.J. and Tiedje, J.M. (1997) Complete reductive dechlorination of 1,2-dichloropropane by anaerobic bacteria. Appl. Environ. Microbiol., 63, 2870-2875.

8. [No authors listed] (1999) 1,2-Dichloropropane. IARC Monogr. Eval. Carcinog. Risks Hum., 71 Pt 3, 1393-1400.

9. Toyoda, Y., Takada, T. and Suzuki, H. (2016) Halogenated hydrocarbon solvent-related cholangiocarcinoma risk: biliary excretion of glutathione conjugates of 1,2-dichloropropane evidenced by untargeted metabolomics analysis. Sci. Rep., 6, 24586.

10. Imberti, R., Calabrese, S.R., Emilio, G., Marchi, L. and Giuffrida, L. (1987) Acute poisoning with solvents: chlorinated aliphatic hydrocarbons. Minerva Anestesiol., 53, 399403.

11. Lucantoni, C., Grottoli, S. and Gaetti, R. (1992) 1,2-Dichloropropane is a renal and liver toxicant. Letter. Toxicol. Appl. Pharmacol., 117, 133.

12. World Health Organization (1986) 1,2-Dichloropropane. IARC Monogr. Eval. Carcinog. Risk Chem. Hum., 41, 131147.

13. Di Nucci, A., Imbriani, M., Ghittori, S., Gregotti, C., Baldi, C., Locatelli, C., Manzo, L. and Capodaglio, E. (1988) 1,2Dichloropropane-induced liver toxicity: Clinical data and preliminary studies in rats in The Target Organ and the Toxic Process. Springer, pp. 370-374.

14. Larcan, A., Lambert, H., Laprevote, M.C. and Gustin, B. (1976) Acute poisoning induced by dichloropropane. Acta Pharmacol. Toxicol. (Copenh.), 41 Suppl 2, 330.

15. Pozzi, C., Marai, P., Ponti, R., Dell'Oro, C., Sala, C., Zedda, S. and Locatelli, F. (1985) Toxicity in man due to stain removers containing 1, 2-dichloropropane. Br. J. Ind. Med., 42, 770-772.

16. Umeda, Y., Matsumoto, M., Aiso, S., Nishizawa, T., Nagano, K., Arito, H. and Fukushima, S. (2010) Inhalation carcinogenicity and toxicity of 1,2-dichloropropane in rats. Inhal. Toxicol., 22, 1116-1126.

17. Matsumoto, M., Umeda, Y., Take, M., Nishizawa, T. and Fukushima, S. (2013) Subchronic toxicity and carcinogenicity studies of 1,2-dichloropropane inhalation to mice. Inhal. Toxicol., 25, 435-443. 
18. Benbrahim-Tallaa, L., Lauby-Secretan, B., Loomis, D., Guyton, K.Z., Grosse, Y., El Ghissassi, F., Bouvard, V., Guha, N., Mattock, H. and Straif, K.; International Agency for Research on Cancer Monograph Working Group (2014) Carcinogenicity of perfluorooctanoic acid, tetrafluoroethylene, dichloromethane, 1,2-dichloropropane, and 1,3-propane sultone. Lancet Oncol., 15, 924-925.

19. Marcus, Y., Shefer, G. and Stern, N. (2013) Adipose tissue renin-angiotensin-aldosterone system (RAAS) and progression of insulin resistance. Mol. Cell. Endocrinol., 378, 1-14.

20. Yang, W., Yu, X., Zhang, Q., Lu, Q., Wang, J., Cui, W., Zheng, Y., Wang, X. and Luo, D. (2013) Attenuation of streptozotocin-induced diabetic retinopathy with low molecular weight fucoidan via inhibition of vascular endothelial growth factor. Exp. Eye Res., 115, 96-105.

21. Yang, Z., Wang, H., Jiang, Y. and Hartnett, M.E. (2014) VEGFA activates erythropoietin receptor and enhances VEGFR2-mediated pathological angiogenesis. Am. J. Pathol., 184, 1230-1239.

22. Barot, M., Gokulgandhi, M.R., Patel, S. and Mitra, A.K. (2013) Microvascular complications and diabetic retinopathy: recent advances and future implications. Future Med. Chem., 5, 301-314.

23. Senger, D.R., Galli, S.J., Dvorak, A.M., Perruzzi, C.A., Harvey, V.S. and Dvorak, H.F. (1983) Tumor cells secrete a vascular permeability factor that promotes accumulation of ascites fluid. Science, 219, 983-985.

24. Shibuya, M. (2006) Vascular endothelial growth factor (VEGF)-Receptor2: its biological functions, major signaling pathway, and specific ligand VEGF-E. Endothelium, 13, 6369.

25. Takekoshi, K., Isobe, K., Yashiro, T., Hara, H., Ishii, K., Kawakami, Y., Nakai, T. and Okuda, Y. (2004) Expression of vascular endothelial growth factor (VEGF) and its cognate receptors in human pheochromocytomas. Life Sci., 74, 863-871.

26. Smyth, H.F., Jr., Carpenter, C.P., Weil, C.S., Pozzani, U.C., Striegel, J.A. and Nycum, J.S. (1969) Range-finding toxicity data: List VII. Am. Ind. Hyg. Assoc. J., 30, 470-476.

27. Park, J., Lee, H., Tran, Q., Mun, K., Kim, D., Hong, Y., Kwon, S.H., Brazil, D., Park, J. and Kim, S.H. (2017) Recognition of transmembrane protein $39 \mathrm{~A}$ as a tumor-specific marker in brain tumor. Toxicol. Res., 33, 63-69.

28. Baruffini, A., Cirla, A.M., Pisati, G., Ratti, R. and Zedda, S. (1989) Allergic contact dermatitis from 1,2-dichloropropane. Contact Derm., 20, 379-380.

29. Hess, A., Bloch, W., Wittekindt, C., Siodladczek, J., Addicks, K. and Michel, O. (2000) Immunohistochemical detection of vascular endothelial growth factor (VEGF) and VEGFreceptors Flt-1 and KDR/Flk-1 in the vestibule of guinea pigs. Neurosci. Lett., 280, 147-150.

30. Ellis, L.M. and Hicklin, D.J. (2008) VEGF-targeted therapy: mechanisms of anti-tumour activity. Nat. Rev. Cancer, 8, 579-591.

31. Hidalgo, M. and Rowinsky, E.K. (2000) The rapamycin-sensitive signal transduction pathway as a target for cancer therapy. Oncogene, 19, 6680-6686.

32. Neufeld, G., Cohen, T., Gengrinovitch, S. and Poltorak, Z.
(1999) Vascular endothelial growth factor (VEGF) and its receptors. FASEB J., 13, 9-22.

33. Bruckner, J., MacKenzie, W.F., Ramanathan, R., Muralidhara, S., Kim, H.J. and Dallas, C.E. (1989) Oral toxicity of 1,2dichloropropane: acute, short-term, and long-term studies in rats. Fundam. Appl. Toxicol., 12, 713-730.

34. Fiaccadori, E., Maggiore, U., Rotelli, C., Giacosa, R., Ardissino, D., De Palma, G., Bergamaschi, E. and Mutti, A. (2003) Acute renal and hepatic failure due to accidental percutaneous absorption of 1,2-dichlorpropane contained in a commercial paint fixative. Nephrol. Dial. Transplant., 18, 219-220.

35. Kumagai, S., Kurumatani, N., Arimoto, A. and Ichihara, G. (2013) Cholangiocarcinoma among offset colour proof-printing workers exposed to 1,2-dichloropropane and/or dichloromethane. Occup. Environ. Med., 70, 508-510.

36. Kubo, S., Nakanuma, Y., Takemura, S., Sakata, C., Urata, Y., Nozawa, A., Nishioka, T., Kinoshita, M., Hamano, G., Terajima, H., Tachiyama, G., Matsumura, Y., Yamada, T., Tanaka, H., Nakamori, S., Arimoto, A., Kawada, N., Fujikawa, M., Fujishima, H., Sugawara, Y., Tanaka, S., Toyokawa, H., Kuwae, Y., Ohsawa, M., Uehara, S., Sato, K.K., Hayashi, T. and Endo, G. (2014) Case series of 17 patients with cholangiocarcinoma among young adult workers of a printing company in Japan. J. Hepatobiliary Pancreat. Sci., 21, 479-488.

37. Eliceiri, B.P., Paul, R., Schwartzberg, P.L., Hood, J.D., Leng, J. and Cheresh, D.A. (1999) Selective requirement for Src kinases during VEGF-induced angiogenesis and vascular permeability. Mol. Cell, 4, 915-924.

38. Fadouloglou, V.E., Balomenou, S., Aivaliotis, M., Kotsifaki, D., Arnaouteli, S., Tomatsidou, A., Efstathiou, G., Kountourakis, N., Miliara, S., Griniezaki, M., Tsalafouta, A., Pergantis, S.A., Boneca, I.G., Glykos, N.M., Bouriotis, V. and Kokkinidis, M. (2017) Unusual $\alpha$-carbon hydroxylation of proline promotes active-site maturation. J. Am. Chem. Soc., 139, 5330-5337.

39. Bae, C.J., Shim, S.B., Jee, S.W., Lee, S.H., Kim, M.R., Lee, J.W., Lee, C.K. and Hwang, D.Y. (2010) IL-6, VEGF, KC and RANTES are a major cause of a high irritant dermatitis to phthalic anhydride in C57BL/6 inbred mice. Allergol. Int., 59, 389-397.

40. Carmeliet, P. (2000) Mechanisms of angiogenesis and arteriogenesis. Nat. Med., 6, 389-395.

41. Cohen, T., Nahari, D., Cerem, L.W., Neufeld, G. and Levi, B.Z. (1996) Interleukin 6 induces the expression of vascular endothelial growth factor. J. Biol. Chem., 271, 736-741.

42. Dutta, P.R. and Maity, A. (2007) Cellular responses to EGFR inhibitors and their relevance to cancer therapy. Cancer Lett., 254, 165-177.

43. Kumagai, S., Kurumatani, N., Arimoto, A. and Ichihara, G. (2013) Cholangiocarcinoma among offset colour proofprinting workers exposed to 1,2-dichloropropane and/or dichloromethane. Occup. Environ. Med., 70, 508-510.

44. Kudo, S., Takemura, S., Tanaka, S., Shinkawa, H., Kinoshita, M., Hamano, G., Ito, T., Koda, M. and Aota, T. (2018) Occupational cholangiocarcinoma caused by exposure to 1,2dichloropropane and/or dichloromethane. Ann. Gastroenterol. Surg., 2, 99-105. 